\title{
EDITORIAL
}

\section{Getting the rehabilitation message across: emerging barriers and positive health benefits}

\author{
S.M. Smith* and M.R. Partridge ${ }^{\#}$
}

$\mathbf{T}$ he world's press frequently contains stories of failed rehabilitation attempts [1] by media personalities, and popular songs on this topic can galvanize strong views [2]. Such events highlight the popularisation of a faulty view that rehabilitation offers only a marginal opportunity for benefit and as such should be avoided at all costs. It is unclear if such scepticism, reinforced by the media, impacts upon those with long-term illness and whether it limits, for example, what pulmonary and cardiac rehabilitation programmes have to offer. In a recent local Primary Care Trust chronic obstructive pulmonary disease (COPD) service evaluation report, patients voiced their concern over the term "rehab" [3] as they believe that there is stigma attached to the term. This previously unrecognised concern may form a new barrier to pulmonary rehabilitation programmes. Clearly, any such concern needs to be addressed as these are interventions of great benefit to our patients [4,5]. However as recruitment and retention of patients into rehabilitation programmes is not easy, as a specialty we need to reflect upon the terminologies we use and how best we "sell" or market these interventions to our patients.

\section{COPD AND REHABILITATION}

COPD represents a global health burden [6] and will move from being the 12th cause to the 5th cause of disability adjusted-life years lost by the year 2020 [7]. In the UK, $>5 \%$ of all deaths have been attributed to COPD and up to one in eight emergency hospital admissions may be due to the condition [8]. Patients who experience acute exacerbations of COPD have: 1) more frequent visits to the emergency department and hospitalisation $[9,10]$; 2) a more rapid decline in lung function [11]; and 3) a reduced quality of life [12]. Pulmonary rehabilitation, which contains elements of group support, education and exercise therapy, has been shown to improve some outcomes [13-15] and is strongly promoted by health charities and recommended in national and international guidelines. However, even when patients are appropriately selected for pulmonary rehabilitation, nonadherence to COPD rehabilitation programmes is not uncommon. In one study [16], 55 patients were regarded as "adherent" in that they completed the whole programme whilst 36 either declined the programme or started the

${ }^{*}$ St Mary's Hospital, Imperial College Healthcare NHS Trust, and ${ }^{*}$ Charing Cross Hospital, Imperial College London, NHLI Division, London, UK.

CORRESPONDENCE: S.M. Smith, Chest and Allergy, St Mary's Hospital, Imperial College Healthcare NHS Trust, London, W2 1NY, UK. E-mail: sheree.smith@imperial.nhs.uk programme but did not complete the course. Those in the latter group were more likely to be current smokers and less likely to use regular maintenance therapy. They were also more likely to be divorced and live alone or in rented accommodation but there was no significant difference between disease severity, exercise capacity or quality of life. Another study [17] investigated why patients declined to take part in a research project that involved pulmonary rehabilitation, and showed that the pulmonary rehabilitation was more likely to be the barrier as opposed to the fact that it was a research project. Reported barriers included travel problems, location of the rehabilitation course, previous negative experience of the hospital or healthcare and a variable perception of the possible benefits to the patient. A US study [18] has similarly shown that those who live $>36$ miles away compared with $<6$ miles away were less likely to be adherent.

Such nonparticipation is not of course unique to pulmonary rehabilitation and many patients similarly fail to attend cardiac rehabilitation. The factors influencing attendance in that condition relate to being older, less aware of factors such as their cholesterol values, unemployment and again perceptions of possible benefit [19]. In addition to these factors, another study suggested that being physically inactive at admission might also be predictive of drop out by females [20]. Preceding activity levels and perception of what rehabilitation may involve may also act as factors, especially in patients with COPD who may perceive the disease as being self induced and where exercise may be an alien experience and one which is thought to be impossible. A perception that pulmonary rehabilitation would be vigorous, floor based and strenuous might be a barrier especially to patients who had a poor self image or self confidence related to exercise. The perception that pulmonary rehabilitation is associated with gyms and sport may appear particularly threatening [17]. Psychosocial assessment prior to referral to rehabilitation may play an important role in enhancing attendance and ongoing participation. Other studies investigating the predictors of rehabilitation programme attendance have found that depression and anxiety play a role in nonparticipation $[18,21,22]$. Psychological comorbidity has been found to be more common amongst those with COPD, especially amongst those experiencing more frequent exacerbations [23]. However, if we can find a way to encourage these individuals to attend, several studies confirm that one of the benefits of exercise is a reduction in depression and symptoms of anxiety [24-26]. 


\section{REBRANDING AND MARKETING}

If we are to help our patients appreciate the benefits of interventions such as pulmonary rehabilitation, we need to think carefully as to how we market the concept to them, including to the sceptics [27]. Many of these patients are elderly and may be patients affected by socioeconomic deprivation and factors such as health literacy need to be taken into consideration. We need to think carefully about the terminology we use and ensure that it is understood by the patients and conveys the correct meaning. The term "COPD" is problematical enough but as respiratory physicians we also refer to "exacerbations" of COPD and yet the word exacerbation means nothing to the majority of patients [28]. The word "rehabilitation" is similarly likely to be misinterpreted and its meaning, even if understood, is likely to reinforce negative connotations, for rehabilitation is surely something that one has to undergo after "illicit or bad" behaviour.

Whilst most of the guidelines relating to pulmonary rehabilitation refer to nonattendance and drop out, few propose strategies to encourage attendance and maintenance of attendance. What we now need to see are good qualitative and quantitative studies looking at how best to engage patients in pulmonary rehabilitation. This is likely to involve patients being provided with sufficient information about a course that enables them to make an informed decision about its advantages. Such information can, of course, be given by a health professional but may be more meaningfully reinforced by appropriately written leaflets (bearing in mind problems of health literacy), by making DVDs or video recordings available to patients or, perhaps better still, by recruitment being undertaken by a patient who has previously been through such a course. After such a process, further attention can then be given to addressing issues of location, frequency of attendance and transport. It should not need to be stressed that such approaches clearly have to be supportive and not in anyway pejorative or judgmental; this especially applies to those who continue to smoke. Furthermore, screening for anxiety and depression may be useful for identifying patients who may need additional support and encouragement to participate in rehabilitation programmes.

We know of GOLD as the Global Initiative for Obstructive Lung Disease [29] but another GOLD, the Growing Old and Living Dangerously council programme [30], has cleverly inspired seniors to participate in health-related and physical activities. Due to its title, this GOLD programme encourages and challenges people to be active and, more importantly, reinforces the belief that a better state of health can be attained at any age when people step out of their comfort zone. In view of the poly-morbidity, which affects so many of these patients [20], a further study is also need to see how we may best incorporate optimal aspects of both types of rehabilitation (cardiac and pulmonary) for the benefit of those with comorbid cardiac and pulmonary conditions. Such an evaluation would also need to include assessment of any reduced gain by patients if not all the patients are perceived to have the same condition. For pulmonary and cardiac patients it is time to rethink the rehabilitation label and to reflect on a more positive, motivating aspect of this health activity rather than conveying it as a punishment undertaken in a gym. Such a shift might necessitate both a new descriptor (such as a
Healthier Lung Course, for example) and new ways of promoting it to patients. In that way we might ensure that an intervention of proven benefit is not only available but utilised by all suitable patients.

\section{CONCLUSION}

COPD is an ongoing condition and pulmonary rehabilitation has been proven to be effective in reducing some of the effects of it. However, recruitment and retention can be problematic and we may be seeing an emerging barrier to this important patient resource as the stigma of being "in rehab" is becoming an issue for some patients. This may reinforce the feeling of hopelessness and the feeling that this is a self inflicted condition, which has been reported by some patients [31]. Rebranding of pulmonary rehabilitation and improved promotion of the concept may facilitate participation in these worthwhile programmes.

\section{STATEMENT OF INTEREST}

None declared.

\section{REFERENCES}

1 ABC News. S. Marikar. Pain, Tears, Vomit, Relapse: the Realities of Rehab Hit Celebrities, Too. January 10, 2009. http:/ /abcnews. go.com/Entertainment/Drugs/Story?id=4110987\&page=1 Last accessed: February 25, 2009.

2 British Broadcasting Corporation. Jackson R. Rehab - behind closed doors. October 27, 2007. www.bbc.co.uk/blogs/fivelivebreakfast/ 2007/10/rehab_behind_closed_doors_1.html Last accessed: February 25, 2009.

3 Hodson M, Parnably C, Lee C, Elkin S, Tempia M. COPD in Westminster: Under one umbrella. London, Westminster PCT, 2008

4 Nici L, Donner C, Wouters E, et al. American Thoracic Society/ European Respiratory Society statement on pulmonary rehabilitation. Am J Respir Crit Care Med 2006; 173: 1390-1413.

5 Ries AL, Bauldoff GS, Carlin BW, et al. Pulmonary Rehabilitation: Joint ACCP/AACVPR Evidenced-Based Clinical Practice Guidelines. Chest 2007; 131: Suppl. 5, 4S-42S.

6 Donaldson GC, Wedzicha JA. COPD exacerbations: 1: Epidemiology. Thorax 2006; 61: 164-168.

7 Murray CJ, Lopez AD. Alternative projections of mortality and disability by cause 1990-2020: Global Burden of Disease Study. Lancet 1997; 349: 1498-1502.

8 British Thoracic Society. Management of exacerbations of COPD. Thorax 2004; 59: Suppl. 1, i131-i56.

9 Bourbeau J, Julien M, Maltais F, et al. Reduction of hospital utilization in patients with chronic obstructive pulmonary disease. Arch Inter Med 2003; 163: 585-591.

10 Wedzicha JA, Donaldson GC. Exacerbations of chronic obstructive pulmonary disease. Respir Care 2003; 48: 1204-1213.

11 Donaldson GC, Seemungal TAR, Bhowmik A, et al. Relationship between exacerbation frequency and lung function decline in chronic obstructive pulmonary disease. Thorax 2002; 57: 847-852.

12 Llor C, Molina J, Naberan K, et al. Exacerbations worsen the quality of life of chronic obstructive pulmonary disease patients in primary healthcare. Int J Clin Pract 2008; 62: 585-592.

13 Hill K, Bansal V, Brooks D, et al. Repeat pulmonary rehabilitation programs confer similar increases in functional exercise capacity to initial programs. J Cardiopulm Rehabil Prev 2008; 28: 410-414.

14 Puhan M, Scharplatz M, Trooster T, et al. Pulmonary rehabilitation following exacerbations of chronic obstructive pulmonary disease. Cochrane Database of Systematic Reviews 2009; CD005305: 1-34. 
15 Griffiths TL, Burr ML, Campbell IA, et al. Results at 1 year of outpatient multidisciplinary pulmonary rehabilitation: a randomised controlled trial. Lancet 2000; 355: 362-368.

16 Young P, Dewse M, Fergusson W, et al. Respiratory rehabilitation in chronic obstructive pulmonary disease: predictors of nonadherence. Eur Respir J 1999; 13: 855-859.

17 Taylor R, Dawson S, Roberts N, et al. Why do patients decline to take part in a research project involving pulmonary rehabilitation? Respir Med 2007; 101: 1942-1946.

18 Fan VS, Giardino ND, Blough DK, et al. Costs of pulmonary rehabilitation and predictors of adherence in the National Emphysema Treatment Trial. COPD 2008; 5: 105-116.

19 Cooper A, Lloyd G, Weinman J, et al. Why patients do not attend cardiac rehabilitation: role of intentions and illness beliefs. Heart 1999; 82: 234-236.

20 Worcester MU, Murphy BM, Mee VK, et al. Cardiac rehabilitation programmes: predictors of non-attendance and drop-out. Eur J Cardiovac Preve Rehabil 2004; 11: 328-335.

21 Sabit R, Griffiths TL, Watkins AJ, et al. Predictors of poor attendance at an outpatient pulmonary rehabilitation programme. Respir Med 2008; 102: 819-824.

22 Casey E, Hughes JW, Waechter D, et al. Depression predicts failure to complete phase II cardiac rehabilitation. J Behav Med 2008; 31: 421-431.

23 QuintJK, Baghai-Ravary R, Donaldson GC, et al. Relationship between depression and exacerbations in COPD. Eur Respir J 2008; 32: 53-60.
24 Alexopoulos GS, Sirey JA, Raue PJ, et al. Outcomes of depressed patients undergoing inpatient pulmonary rehabilitation. Am J Geriatr Psychiatry 2006; 14: 466-475.

25 Paz-Diaz H, Montes de Oca M, Lopez JM, et al. Pulmonary rehabilitation improves depression, anxiety, dyspnea and health status with COPD. Am J Phys Med Rehabil 2007; 86: 30-36.

26 Laederach-Hofmann K, Roher-Gubeli R, Messerli N, et al. Comprehensive rehabilitation in chronic heart failure-better psycho-emotional status related to quality of life, brain natriuretic peptide concentrations, and clinical severity of disease. Clin Invest Med 2007; 30: E54-E62.

27 Fischer MJ, Scharloo M, Abbink JJ, et al. Participation and drop-out in pulmonary rehabilitation: a qualitative analysis of the patient's perspective. Clin Rehabil 2007; 21: 212-221.

28 Kessler R, Stahl E, Vogelmeier C, et al. Patient understanding, detection and experience of COPD exacerbations: an observational, interview-based study. Chest 2006; 130: 133-142.

29 Global Initiative for Chronic Obstructive Lung Disease. www.goldcopd.com Last accessed: September 17, 2009.

30 Brisbane City Council. GOLD: Growing Old and Living Dangerously. www.brisbane.qld.gov.au/BCC:STANDARD::pc= PC_2018 Last accessed: September 17, 2008. Last updated: April 17, 2009.

31 Oliver SM. Living with failing lungs: the doctor-patient relationship. Fam Pract 2001; 18: 430-439. 